\title{
Snuffelgidse op die Web: die gebruik van klassifikasie vir die organisering van inligtingsbronne op die Internet
}

\author{
M.S. van der Walt \\ Departement Inligtingkunde, Universiteit van Stellenbosch, Privaatsak X1, Matieland, Stellenbosch, 7602 Republiek van Suid-Afrika \\ msvdw@maties.sun.ac.za
}

\begin{abstract}
Browsing guides on the Web: the use of classification for the organisation of information sources on the Internet. An investigation was carried out regarding the question whether systematic arrangement by means of a classification scheme can offer a solution for the problems of information organisation on the Internet. The purpose of the investigation was to establish the extent of present use of classification on the Internet, which systems are being used, what the nature, characteristics and applications of these schemes are and to formulate broad guidelines for classification in this electronic environment. The classification schemes and other retrieval mechanisms of a variety of Internet guides and search engines were analysed. Two groups of schemes were identified: library classifications with notations and other schemes consisting in most cases of alphabetically arranged subject classes. Classification schemes are used for two purposes in guides: the arrangement of entries and in a few cases to provide access points for specific searches. Facilities for keyword searching are provided in the majority of guides, but descriptors from controlled indexing languages are used in very few cases.
\end{abstract}

\begin{abstract}
Ondersoek is ingestel na die vraag of die gebruik van sistematiese rangskikking met behulp van 'n klassifikasiesisteem nie 'n oplossing kan bied vir die probleme van inligtingontsluiting op die Internet nie. Die doel van die ondersoek was om te bepaal wat die omvang van die huidige gebruik van klassifikasie op die Internet is, watter sisteme gebruik word, wat die aard, kenmerke en toepassings van hierdie sisteme is en om breë riglyne vir klassifikasie in hierdie elektroniese omgewing te formuleer. Die klassifikasiesisteme en ander ontsluitingsmeganismes van 'n verskeidenheid van Internetgidse en soekenjins is ontleed. Twee groepe sisteme kan onderskei word: biblioteekklassifikasiesisteme wat oor 'n notasie beskik en ander sisteme wat meestal uit alfabetiesgerangskikte onderwerpsklasse bestaan. Klassifikasiesisteme word vir twee doeleindes in gidse gebruik: die rangskikking van inskrywings en in enkele gevalle om toegangspunte vir spesifieke soektogte te verskaf. Fasiliteite vir sleutelwoordsoektogte kom algemeen voor, maar daar word baie min van deskriptore uit gekontroleerde indekseertale gebruik gemaak.
\end{abstract}

\begin{abstract}
'n Mens hoor dikwels stellings met die strekking dat die Internet ' $n$ ongeorganiseerde, chaotiese versameling van inligtingsbronne bevat en dat dit gevolglik moeilik is om relevante bronne vinnig en doeltreffend op te spoor. Williamson (1997:23) sê byvoorbeeld: '... it is vastly unorganized such that it is difficult to conceptualize, browse, search, filter, or reference the system'. Daar is klaarblyklik 'n behoefte aan meganismes om orde in hierdie chaos te bring.
\end{abstract}

Deur die loop van baie eeue is twee uiteenlopende benaderings tot die organisering (ontsluiting) van inligting ontwikkel deur bibliotekarisse, bibliograwe, indekseerders, argivarisse en ander inligtingspesialiste, naamlik alfabetiese en sistematiese (geklassifiseerde) onderwerpsrangskikking van dokumente of rekords. Die alfabetiese benadering tot inligtingontsluiting is goed gevestig op die Internet in die vorm van soekenjins soos Alta Vista en HotBot wat programmatuur bied vir die uitvoering van sleutelwoordsoektogte.

Die gebruik van sleutelwoorde vir onderwerpstoegang het egter verskeie beperkings, soos die aanwesigheid van sinonieme, homograwe, verskillende grammatiese vorms van woorde en afkortings in natuurlike taal, asook die afwesigheid van hiërargiese struktuur waardeur verwante terme met mekaar in verband gebring word. Hoewel soekenjins verskeie tegnieke, soos afkapping, verskaf om sommige van hierdie probleme die hoof te bied, bly die opsporing van talle nie-relevante bronne en die onvermoë om soektogte sistematies onder verwante terme uit te brei, steeds 'n kopseer vir ernstige soekers na inligting.

Die vraag ontstaan of die gebruik van sistematiese rangskikking met behulp van 'n klassifikasiesisteem nie 'n oplossing kan bied vir die probleme van inligtingontsluiting op die Internet nie. Benewens die uitskakeling van bogenoemde probleme van natuurlike taal is sistematiese rangskikking ook nuttig uit die oogpunt van persone wat nie spesifieke soektogte wil uitvoer nie, maar eerder wil snuffel ('browse'). Die snuffelbenadering tot inligtingsoektogte word algemeen as 'n geldige en belangrike benadering erken (cf. Hawkins 1996 en Hyman 1972).

Verskeie studies het al aangetoon dat klassifikasie, veral in kombinasie met verbale soekterme (gekontroleerde of natuurlike taal) intydse inligtingsherwinning kan verbeter (Chan 1995:10). Daar is dan ook reeds heelwat voorbeelde van ontsluitingstelsels op die Internet wat klassifikasiesisteme gebruik vir die ordening of ontsluiting 
van elektroniese bronne. Enkele bekendes is CyberDewey en CyberStacks(sm), wat tradisionele biblioteekklassifikasiesisteme gebruik, Magellan Internet Guide en Yahoo! Woodward (1996:195-203) gee 'n literatuuroorsig (tans reeds taamlik verouderd!) van klassifikasieprojekte op die Internet. Balas (1996) bespreek 'n aantal toepassings van Dewey op die Internet.

Geklassifiseerde lyste van Internetbronne staan gewoonlik bekend as gidse ('guides' of 'directories') of katalogi. 'n Onlangse ontwikkeling is dat verskeie soekenjins, byvoorbeeld Excite, Infoseek en Webcrawler, hulle geklassifiseerde lyste van gekeurde bronne saam met ander dienste groepeer in breë onderwerpskategorieë en dit dan 'channels' noem (Notess 1997:54). 'n Vergelyking van hierdie 'channels' met die gidse in vroeëre weergawes van die betrokke soekenjins toon dat daar min verskil is tussen die vorige en huidige onderwerpsindelings. Volgens Piontek en Garlock is sogenaamde virtuele biblioteke ("virtual libraries') ook onderwerpsgidse. Hulle definieer gidse as 'any catalog of Internet resources organized in a topical scheme' (1996:20).

Benewens die geklassifiseerde rangskikking kan gidse verder onderskei word van gewone soekenjins soos Alta Vista deurdat die bronne wat ontsluit word volgens bepaalde kriteria geselekteer is. Verdere waardetoevoeging vind dikwels plaas deur beskrywende of evaluatiewe opsommings/besprekings ('reviews') van die bronne. Internetgidse kan dus ook beskryf word as selektiewe bibliografieë van bronne op die Internet. Baie van die, gidse maak ook voorsiening vir sleutelwoordsoektogte deur middel van soekenjins en kan dus as hibriede sisteme beskou word, aangesien die alfabetiese soek- sowel as die sistematiese snuffelbenadering bevredig kan word.

Die doel van hierdie ondersoek was om te bepaal wat die omvang van die gebruik van klassifikasie vir ontsluiting op die Internet is, watter verskillende sisteme gebruik word en wat die aard, kenmerke en toepassings van hierdie sisteme is. Uit so 'n studie kan moontlik ook afgelei word wat die eienskappe van ' $\mathrm{n}$ ideale gids ten opsigte van hierdie aspekte moet wees.

Beide tradisionele biblioteekklassifikasiesisteme en eiesoortige sisteme wat in soekenjins en ander gidse gebruik word, is bestudeer. Die ondersoek is beskrywend van aard; gevolglik word nie beredeneer of klassifikasie 'n doeltreffende en koste-effektiewe metode vir die organisering van die Internet kan wees nie, en die sisteme wat gebruik word, word ook nie sistematies geëvalueer nie. 'n Evaluering van sekere aspekte van die klassifikasiestelsels wat in soekenjins gebruik word, is in 'n vroeëre navorsingsprojek gedoen (Van der Walt 1997).

\section{Metodologie}

Inligting oor klassifikasie op die Internet is versamel deur middel van soektogte op die Internet self, sowel as in konvensionele gedrukte publikasies. Vir laasgenoemde is die LISA- en ERIC-databasisse gebruik.
Daar is gepoog om soveel as moontlik Internetgidse waarin klassifikasie 'n rol speel, op te spoor. Die meeste soekenjins met gidse bevat uitgebreide lyste van gidse. Yahoo! (http://www.yahoo.com/) verskaf byvoorbeeld 'n lys van ongeveer 150 titels onder die opskrif 'Web Directories'. Directory Guide (http://www.directoryguide.com/) is 'n katalogus van 400 soekenjins en gidse, geselekteer uit meer as 'n duisend wat geëvalueer is. Ten einde die omvang van die huidige ondersoek binne perke te hou, was dit dus nodig om die terrein af te baken. Die hoofkriterium vir die seleksie van gidse vir bestudering was dat hulle ' $\mathrm{n}$ algemene onderwerpsdekking moes hê of ten minste 'n breë terrein soos wetenskap en tegnologie of die sosiale wetenskappe moes dek. Volgens hierdie uitgangspunt is alle opgespoorde gidse wat gebruik maak van tradisionele biblioteekklassifikasiesisteme, behalwe enkeles met uiters beperkte onderwerpsdekking, ingesluit. Die belangrikste omvattende lys van hierdie groep gidse word aangetref in Beyond bookmarks: schemes for organizing the Web (McKiernan 1997).

In die geval van gidse wat ander klassifikasiesisteme gebruik, is veral gefokus op gidse wat deur soekenjins aangebied word. Benewens algemene onderwerpsdekking was 'n verdere oorweging by seleksie in hierdie groep of die soekenjin/gids vermeld word op een of meer van die selektiewe lyste van aanbevole soekenjins en gidse wat tydens die soektog raakgeloop is. Op hierdie wyse is gepoog om te verseker dat die belangrikste of mees populêre gidse almal ingesluit word. Verskeie gidse word op Netscape se tuisblad onder die opskrif 'Web guides' vermeld. Verdere belangrike bronne in hierdie verband is Search engine watch (Feldman 1997; Sullivan 1998), Understanding WWW search tools (Liu 1996) en 'n artikel van Collins (1997) in die Library journal se gereelde rubriek 'Webwatch'. Verskeie ander lyste van aanbevole gidse en soekenjins, byvoorbeeld op biblioteke se tuisblaaie, is ook nagegaan.

' $n$ Verdere beperking by die keuse van gidse was dat slegs Engelstalige gidse oorweeg is. Dit het meegebring dat een Italiaanse gids wat UDC gebruik en een Sweedse gids wat volgens alfabetiese onderwerpsklasse gerangskik is, nie ingesluit is nie. Gidse moes ook gratis beskikbaar wees. Op grond van hierdie oorweging is OCLC se NetFirst: The authoritative directory for internet resources, wat op die FirstSearch- en EPIC-dienste beskikbaar is, nie ondersoek nie.

Die tuisblaaie van al die gidse wat vir die doel van die ondersoek geselekteer is, is besoek gedurende Februarie of Maart 1998. Die aard, kenmerke en gebruik van die betrokke klassifikasiesisteme is nagegaan en daar is ook vasgestel watter soekpunte vir spesifieke soektogte verskaf word. Aanvullend tot die gegewens op die tuisblaaie van die gidse is verdere intydse dokumentasie oor die stelsels geraadpleeg. Dit is tipies gekoppel aan die 'Help' of 'About us' skakels. 


\section{Internetgidse waarin klassifikasiesisteme gebruik word}

In hierdie afdeling word 'n uiteensetting gegee van die gidse wat geselekteer is met die oog op die ondersoek. Die gidse word ingedeel volgens die betrokke klassifikasiesisteme. Twee groepe klassifikasiesisteme kan onderskei word: (1) standaard biblioteekklassifikasiesisteme wat oor 'n notasie beskik, soos die Dewey decimal classification (Dewey), die Universal decimal classification (UDC) en die Library of Congress classification (LCC), en (2) ander sisteme, meestal alfabeties-gerangskikte onderwerpsklasse sonder notasie, byvoorbeeld die sisteme wat in Internetsoekenjins gebruik word. Hierdie onderskeid word ook getref deur Vellucci (1996:21).

Ten opsigte van elke gids word die volledige titel en URL verstrek. Die verdere beskrywing bevat besonderhede oor die samesteller/redakteur, organisasie, dekking en die klassifikasiesisteem, in soverre dit uit die beskikbare dokumentasie vasgestel kon word. Baie van die gidse gee egter geen eksplisiete aanduiding van wat alles gedek word nie. Onmiddellik na die lys van gidse in elk van die twee groepe word algemene tendense ten opsigte van die betrokke groep sisteme bespreek. Bevindings oor die toepassing van die klassifikasiesisteme vir rangskikking en soekpunte, asook ander toegangspunte wat in soektogte gebruik kan word, word in Tabel 1 saamgevat.

\section{Gidse wat algemene biblioteekklassifikasiesis- teme gebruik}

\section{Dewey decimal classification}

- Alastair Smiths Bookmarks on the Net: Sites by DDC URL: http://www.vuw.ac.nz/ agsmith/bkmark.htm

Persoonlike tuisblad van die samesteller wat verbonde is aan die Universiteit van Victoria, Nieu-Seeland. Die klassifikasie is baie breed, meestal net twee of drie syfers.

- Blue Web'n Content Categories

URL: http://www.kn.pacbell.com/wired/bluewebn/categories.html

Dek onderrigmateriaal, naslaanwerke en ander materiaal wat as leerhulpmiddels gebruik kan word. Die klassifikasie is relatief breed, tot die derde syfer.

- BUBL LINK: Browse LINK by DDC

URL: http://link.bubl.ac.uk/ISC2

BUBL is 'n nasionale inligtingsdiens vir die Britse hoër onderwysgemeenskap. LINK is 'n selektiewe katalogus van Internetbronne. Aanvanklik is die UDC gebruik vir die gids, maar die diens is onlangs herorganiseer en het oorgeskakel na Dewey. Klassifikasie is baie spesifiek.

- Canadian Information by Subject URL: http://www.nlc-bnc.ca/caninfo/ecaninfo.htm Hierdie gids word saamgestel deur die nasionale biblioteek van Kanada. Dit dek bronne van en oor Kanada. Die klassifikasie is ' $n$ aanpassing van Dewey. Die notasie lyk meer na UDC, aangesien een- en tweesyfer notasies dikwels gebruik word. Klassifikasie is oor die algemeen breed.

- CyberDewey

URL: http://ivory.lm.com/ mundie/DDHC/DDH.html

Dit is nie duidelik of die gids nog bygehou word nie, aangesien daar slegs 'n kopieregdatum van 1995 in die dokumentasie verskyn. Klassifikasie is relatief breed, maar daar kom notasies van ten minste ses syfers voor.

- Dewey Jr.

URL: http://www.tempe.gov/library/dewey.htm

Saamgestel by Tempe Openbare Biblioteek, Arizona, as 'n hulpmiddel vir leerlinge se huiswerkopdragte. Breë klassifikasie.

- GNOSIS: Global Network of Silicon Information Services

URL: http://www.aimnet.com/ clancey/gnosis/

Vroeër bekend as Patrick's Subject Catalog. Of dit op datum gehou is, is onseker - die mees onlangse hersiening van bladsye het tussen Augustus 1996 en Januarie 1997 plaasgevind. Klassifiseer taamlik spesifiek.

- The Internet Public Library

URL: http://www.ipl.org/reading/books/

Meer as 6500 volteksboeke word gedek. Die gids is nog 'n beta weergawe. Dit word ontwikkel as 'n gesamentlike projek van die Universteit van Michigan en Humanities Text Initiative. Die 20ste uitgawe van Dewey word met aanpassings gebruik. Meer as een nommer word dikwels aan 'n boek toegeken. 'n Onderhoud met die personeel van die gids is gepubliseer in American libraries (Internet Public Library 1997).

- Internet Resources in Dewey Decimal Order with DDC Subjects

URL: http://www.mcpl.lib.mo.us/dewey.htm

Saamgestel by die Mid-Continent Openbare Biblioteek, V.S.A. Die klassifikasie is relatief breed, maar sessyfernotasies kom voor.

- Internet Resources: Subject List in Classification Order URL:http://chandra.chester.ac.uk/ smilne/chesweb2. htm

Saamgestel by die Universiteitskollege van Chester, Brittanje. Volgens die dokumentasie is die bronne geselekteer volgens die behoeftes van die personeel en studente van die kollege, maar daar is baie wat van nut sal wees vir 'n wyer groep gebruikers. Die klassifikasie is skynbaar relatief breed tot taamlik spesifiek in sommige gevalle.

- Library without Walls

URL: http://www.voicenet.com/ srussell/student.html

Saamgestel by Mt. Laurel Hartford Skool, V.S.A. Die bronne word geselekteer met die oog op graad 5- en 6leerlinge se behoeftes by die uitvoer van werkopdragte. Die klassifikasie is baie breed, gewoonlik net twee syfers.

- Mr. Duis' Topic Finder URL: http://www.oclc.org/oclc/fp/mrdui/ URL: http://www.scit.wlv.ac.uk/wwlib/ 
Tabel 1 Snuffelbenaderings en soekpunte in Internetgidse

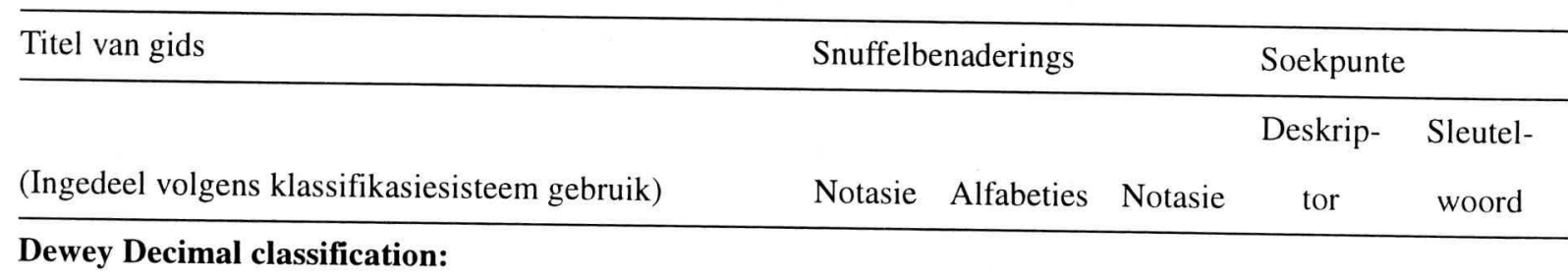

Alistair Smith's Bookmarks on the Net

Blue Web'n Content Categories

BUBL LINK

Canadian Information by Subject

CyberDewey (Mundie)

Dewey Jr. (Tempe Public Library)

GNOSIS (Patrick's Subject Catalogue)

The Internet Public Library

Internet resources in Dewey Decimal Order (Mid-

Continent P L)

Internet resources: Subject List (Univ College

Chester)

Library without Walls (Mt Laurel Hartford School)

Mr. Dui's Topic Finder (OCLC NetFirst)

Net Sites by the Numbers (Tempe Public Library)

The UK Web Library (Wolverhampton Web Library)

Webrary (Morton Grove Public Library)

\section{Universal Decimal Classification:}

Directory of Networked Resources (NISS)

Social Science Information Gateway (SOSIG)

\section{Library of Congress Classification:}

CyberStacks(sm) (McKiernan)

Internet Resources arranged by the LCC System

(Cardinal Stritch)

Scout Report Signpost (Univ.of Wisconsin-Madison)

Subject Web Sites (Cerro Coso Community College)

T.F.Mills Home Page

\section{Nederlandse Basisclassificatie:}

DutchESS (Dutch Electronic Subject Service)

\section{Ander sisteme (eie aan betrokke gids):}


Tabel 1 Snuffelbenaderings en soekpunte in Internetgidse

\begin{tabular}{|c|c|c|c|c|c|}
\hline \multirow{2}{*}{$\begin{array}{l}\text { Titel van gids } \\
\text { (Ingedeel volgens klassifikasiesisteem gebruik) }\end{array}$} & \multicolumn{3}{|c|}{ Snuffelbenaderings } & \multicolumn{2}{|l|}{ Soekpunte } \\
\hline & Notasie & Alfabeties & Notasie & $\begin{array}{c}\text { Deskrip- } \\
\text { tor }\end{array}$ & $\begin{array}{l}\text { Sleutel- } \\
\text { woord }\end{array}$ \\
\hline The Argus Clearinghouse & & - & & & $\bullet$ \\
\hline Britannica Internet Guide & & $\bullet$ & & & • \\
\hline Excite: Channels & & - & & & • \\
\hline G.O.D. (Global Online Directory) & & • & & & • \\
\hline Galaxy: Directory & & - & & & - \\
\hline INFOMINE (University of California) & & - & & - & - \\
\hline Infoseek: Channels & & - & & & • \\
\hline Librarians' Index to the Internet & & - & & & - \\
\hline LookSmart & & & & & • \\
\hline Lycos: Web guides & & - & & & - \\
\hline Lycos Top 5\% (Point): Topic directory & & & & & - \\
\hline Magellan Internet Guide: Web reviews & & - & & & $\bullet$ \\
\hline The Mining Company & & - & & & $\bullet$ \\
\hline Nerd World: Internet subject index & & - & & & • \\
\hline NetGuide: Guides & & - & & & • \\
\hline Search.com (clnet): Speciality searches & & • & & & - \\
\hline Snap! & & • & & & - \\
\hline Webcrawler: Channels & & - & & & $\bullet$ \\
\hline What-u-seek: Channels & & - & & & - \\
\hline The WWW Virtual Library & & - & & & \\
\hline Yahoo! & & - & & & - \\
\hline
\end{tabular}

Dit is ontwikkel as 'n prototipe koppelvlak vir die NetFirst-databasis, OCLC se katalogus van bronne op die Internet. Tot op datum is dit blykbaar nog nie aan NetFirst gekoppel nie, maar ontsluit net 'n klein seleksie van rekords vir demonstrasiedoeleindes. In NetFirst self word volledige bibliografiese rekords angetref, met een of meer klassifikasienommers vir elke bron wat ontsluit word. Die klassifikasie is baie spesifiek.

- Net Sites by the Numbers

URL: http://www.tempe.gov/netsites/

Saamgestel by Tempe Openbare Biblioteek, Arizona. Die klassifikasie is relatief breed.

- UK Web Library - Searchable Classified Catalogue of UK Web Sites

URL: http:/www.scit.wlv.ac.uk/wwlib/
Ook bekend as Wolverhampton Web Library (WWLib). Die gids word saamgestel by die School of Computing and Information Technology van die Universiteit van Wolverhampton. Dit is nie uit die dokumentasie duidelik of die gids gereeld bygewerk word nie. Klassifikasie is spesifiek en volgens die 20ste uitgawe van Dewey.

- Webrary

URL: http://www.webrary.org/ref/weblinksmenu.html Saamgestel by die Morton Grove Openbare Biblioteek, Illinois. Breë klassifikasie word gebruik.

\section{Universal decimal classification}

- Directory of Networked Resources

URL: http://www.niss.ac.uk/subject/index.html 
Saamgestel deur NISS (National Information Services and Systems), wat 'n inligtingsdiens aan die Britse opvoedkundige en navorsingsgemeenskap lewer. Die klassifikasie is baie breed, selde meer as drie syfers.

- Social Science Information Gateway (SOSIG)

URL: http://sosig.esrc.bris.ac.uk/

SOSIG is 'n katalogus van Internetbronne van belang vir onderwys en navorsing op die terrein van die sosiale wetenskappe. UDC-nommers word as deel van die bibliografiese rekords ingevoer, maar snuffelsoektogte kan nie direk volgens die notasie gedoen word nie.

\section{Library of Congress classification}

- CyberStacks(sm)

URL:http://www.public.iastate.edu/ CYBERSTACKS/

Hierdie gids wat deur Gerry McKiernan van die Iowa State Universiteit saamgestel word, dek hoofsaaklik die breë terrein van wetenskap en tegnologie (LCC-klasse Q-T). Die klem by seleksie van bronne is op materiaal van belang vir akademici en navorsers. Die stelsel is tans nog in ' $n$ ontwikkelingsfase en word in die dokumentasie as 'n prototipe aangedui. Verkorte LCC-klasnommers word gebruik. Die ontwikkeling van die gids word uiteengesit deur McKiernan (1996) en dit word krities bespreek deur Pat Ensor (1996).

- Internet Resources arranged by the Library of Congress Classification System

URL: http://www.stritch.edu/ csclib/index.html

Hierdie gids is 'n produk van die Cardinal Stritch Universiteit se biblioteek. Baie breë notasies word toegeken.

- Scout Report Signpost

URL: http://www.signpost.org/signpost/index.html

Hierdie gids is 'n uitvloeisel van 'n projek van die Departement Rekenaarwetenskap van die Universiteit van Wisconsin-Madison. Bronne word vir opname in die databasis gekeur met die behoeftes van die hoër onderwyssektor in gedagte. Klassifikasie is breed - slegs die letternotasies van LCC word gebruik.

- Subject Web Sites

URL: http://www.cc.cc.ca.us/library/websites.htm

Die Learning Resource Centre van die Cerro Coso Gemeenskapskollege is verantwoordelik vir hierdie gids. Klassifikasie is baie breed, meestal net een letter.

- T.F. Mills Home Page

URL: http://www.du.edu/ tomills/

Mills is verbonde aan die Universiteit van Denver. Klassifikasie is baie breed. Die notasie kom net op die tuisblad voor en nie as opskrifte in die lys van bronne nie.

Uit die voorafgaande uiteensetting is dit duidelik dat tradisionele biblioteekklassifikasiesisteme reeds goed gevestig is as hulpmiddels om bronne op die Internet te organiseer, hoewel sommige stelsels nog as prototipes beskryf word. Daar is 'n wye spektrum van omgewings waar hulle gebruik word: openbare, akademiese, nasionale en skoolbiblioteke, inligtingsdienste vir navorsers en selfs persoonlike inligtingstelsels. Die Dewey decimal classification geniet klaarblyklik die meeste aanhang. Dit is veelseggend dat BUBL oorgeslaan het van UDC na Dewey.

Meeste van die gidse gebruik aangepaste weergawes van die klassifikasiesisteme. Op enkele uitsonderings na word verkorte klassifikasienommers gebruik, met die gevolg dat die vlak van spesifisiteit in die gidse nie baie hoog is nie. Soms word nie veel meer as die eerste of tweede vlak van hiërargiese onderverdeling gebruik nie. Hierdie benadering van breë klassifikasie is in orde in die geval van openbare en skoolbiblioteke, en solank as wat die aantal bronne wat in ' $n$ gids ontsluit word taamlik beperk is. In akademiese en navorsingsomgewings, veral namate die versamelings bronne met die loop van die jare 'n groot omvang kan aanneem, gegewe die groot massas bronne wat reeds op die Internet beskikbaar is, mag dit ' $n$ goeie beleid wees om van die begin af so spesifiek te klassifiseer as wat die betrokke sisteem toelaat.

\section{Gidse wat ander klassifikasiesisteme gebruik} Nederlandse Basisclassificatie

\section{- DutchESS (Dutch Electronic Subject Service)}

URL: http://www.konbib.nl/dutchess/nbc_main.html Hierdie stelsel is gesetel by die Koninklijke Bibliotheek in Den Haag. 'n Nederlandse en Engelse weergawe is beskikbaar. Dit is nie bekend of dit in Nederlandse biblioteke gebruik word nie. Die klassifikasie is taamlik breed. Die notasie bestaan uit 'n tweesyferkode wat vir vakgebiede voorsiening maak en dit word dan desimaal onderverdeel met ' $n$ verdere twee syfers vir onderafdelings, byvoorbeeld 31 Mathematics, 31.01 History of mathematics, 31.73 Mathematical statistics.

\section{Alfabetiese-geklassifiseerde sisteme}

Die onderstaande soekenjins en enkele ander gidse soos The Argus Clearinghouse en The WWW Virtual Library gebruik elk hulle eie unieke klassifikasiesisteme. Die algemeen bekende soekenjin HotBot het ook 'n gids op sy tuisblad ('Browse by subject'), maar dit word nie by die lys ingesluit nie aangesien HotBot bloot 'n koppeling na LookSmart se gids verskaf. Verskillende terme word op die tuisblaaie van soekenjins gebruik om hulle gidse te identifiseer. Die mees algemeen gebruikte terme is 'guides', 'channels' en 'directories'. Waar toepaslik word die betrokke term in Tabel 1 na die naam van die soekenjin aangedui.

- AOL NetFind (http://www.aol.com/netfind/)

- The Argus Clearinghouse (http://www.clearinghouse.net/)

- Britannica Internet Guide (http://www.ebig.com/)

- Excite (http://www.exite.com/)

- G.O.D. (Global Online Directory) (http://www.god.co.uk/)

- Galaxy (http://galaxy.einet.net/galaxy.html)

- INFOMINE (http://lib-www.ucr.edu/)

- Infoseek (http://www.infoseek.com/)

- Librarians' Index to the Internet 
(http://sunsite.berkeley.edu/InternetIndex/)

- LookSmart (http://www.looksmart.com/)

- Lycos (http://www.lycos.com/)

- Lycos Top 5\% (http://point.lycos.com/categories/)

- Magellan Internet Guide (http://www.mckinley.com/)

- The Mining Company (http://home.miningco.com/mbody.htm)

- Nerd World (http://www.nerdworld.com/)

- NetGuide (http://www.netguide.com/)

- Search.com (http://www.search.com/)

- Snap! (http://home.snap.com/)

- Webcrawler (http://www.webcrawler.com/)

- What-u-seek (http://www.whatuseek.com:80/)

- The WWW Virtual Library (http://vlib.stanford.edu/Overview.html)

- Yahoo! (http://www.yahoo.com/)

Callery (1996) gee 'n uiteensetting van hoe Yahoo! saamgestel word en hoe die klassifikasiesisteem ontwikkel word.

Dit is nie sinvol om die kenmerke van bogenoemde gidse se klassifikasiesisteme individueel te bespreek nie angesien hulle, op enkele uitsonderings na, almal dieselfde patroon volg, naamlik wat bekend staan as 'n alfabetiesgeklassifiseerde rangskikking. Dit behels die alfabetiese rangskikking van die onderwerpsopskrifte wat as hoofklasse gebruik word, gewoonlik op die tuisblad van die betrokke soekenjin/gids, waarna die ondergeskikte klasse binne elke kategorie op die opeenvolgende vlakke laer af in die hiërargie telkens ook alfabeties gerangskik word.

So kry ons byvoorbeeld in Yahoo! op die boonste hiërargiese vlak: Arts and Humanities, Business and Economy, Computers and Internet, Education, Entertainment, Government, Health, News and Media, Recreation and Sports, Reference, Regional, Science, Social Science, Society and Culture. Arts word weer onderverdeel in: Art History, Artists en Arts Therapy tot by Visual Arts, terwyl Art History op sy beurt verdeel word in 'n verdere reeks onderwerpe in alfabetiese volgorde.

Die uitsonderings op hierdie patroon is AOL NetFind, LookSmart en Lycos Top 5\% wat soortgelyke onderwerpsklasse as die ander soekenjins gebruik, maar dit rangskik in 'n volgorde wat skynbaar op geen logiese beginsel berus nie. Britannica Internet Guide se hoofklasse is alfabeties gerangskik, maar by die volgende vlakke van onderverdeling het die samestellers se alfabet skynbaar effens deurmekaar geraak!

In 'n vorige navorsingsprojek, waartydens die struktuur van die klasse van 14 van bogenoemde gidse ondersoek is (Van der Walt 1997), is vasgestel dat slegs 15 konsepte by die helfte of meer van die gidse se hoofklasse voorgekom het, naamlik Business (14), Education (13), Computersing (12), Sports (12), Art(s) (11), Health (11), Science(s) (11), Entertainment (10), News/Daily Press (9), Government (8), Travel (8), Internet (7), Lifestyle/Life \& Style/ Living (7), Recreation (7) en Reference (7). Daar is klaarblyklik 'n redelike mate van konsensus by die samestellers van die soekenjins/gidse dat hierdie 15 konsepte die belangstellingsvelde van hulle gebruikers in so 'n mate weerspieël, dat hulle as hoofklasse op die tuisblaaie behoort te verskyn. 'n Verdere 26 konsepte het by twee tot ses van die gidse se hoofklasse voorgekom, naamlik Shopping (6), Technology (6), Medicine (5), Places/Regional/World (5), Social science(s) (5), Culture (4), Humanities (4), Investing/Investment (4), Leisure (4), Society/Social issues (4), Community (3), Financel Financial services (3), Games (3), Hobbies (3), Kids (3), Law (3), People/Persons (3), Politics (3), Auto(s) (2), Commerce (2), Communication(s) (2), Engineering (2), Fitness (2), Home (2), Music (2) en Nature (2). 'n Verdere 29 terme het elk slegs een keer in die hoofklasse voorgekom.

'n Vergelyking van hierdie konsepte met die hoofklasse van Dewey, UDC en LCC toon dat uit die eerste groep van 15 slegs drie konsepte ook voorkom as hoofklasse in een of meer van die biblioteekklassifikasiesisteme, naamlik Art en Science (by Dewey, UDC en LCC) en Education (by LCC). In die tweede groep konsepte is ' $n$ verdere ses wat ook by die biblioteeksisteme as hoofklasse angetref word, naamlik Technology en Social sciences (by Dewey, UDC en LCC) en Medicine, Law, Politics en Music (by LCC).

Dit is duidelik dat daar taamlik drastiese verskille tussen die hoofklasse van die tradisionele biblioteeksisteme en dié van die soekenjins is. Vergelykende studies tussen LCC, Dewey en Yahoo! (Vizine-Goetz 1996) en tussen LCC, Dewey en drie Internetgidse (Yahoo!, Magellan en The Whole Internet Catalog) (Dodd 1996:280-281), bevestig hierdie gevolgtrekking. Die biblioteeksisteme gebruik konsekwent slegs vakgebiede of breë groeperings van vakgebiede as hoofklasse, terwyl die sisteme van die soekenjins 'n mengsel van vakname en spesifieke onderwerpe bevat, wat soms baie laer af in die hiërargie van 'n klas in Dewey, UDC of LCC voorkom. Verder gebruik sommige soekenjins ook terme wat dui op tipes dokumente (vormbegrippe), byvoorbeeld News en Reference, geografiese begrippe, byvoorbeeld Places en World, en selfs teikengebruikersgroepe, byvoorbeeld For Kids, as hoofklasse. In 'n vroeëre ondersoek van die struktuur van 'n aantal gidse het Dodd (1996:279) ook die vermenging van onderwerps- en vormbegrippe waargeneem. So 'n vermenging van verskillende kategorieë van begrippe op dieselfde vlak van indeling druis in teen alle beginsels van klassifikasie. Dit sou egter interessant wees om deur middel van 'n Internetgebruikerstudie te probeer vasstel in watter mate die indelings van die soekenjins aanvaar word en voldoen aan die behoeftes van soekers.

In die navorsingsprojek waarna in die voorafgaande paragrawe verwys is, is ook nagegaan wat die vlak van spesifisiteit in die gidse van soekenjins is. Daar is deur middel van 'n aantal steekproewe bevind dat die meerderheid van die gidse ( 9 uit die 14) voorsiening maak vir drie en by sommige onderwerpsgebiede tot vier vlakke van hiërargiese onderverdeling (die hoofklasse ingesluit). Slegs Yahoo! bied soms tot vyf vlakke van onderverdeling. Ook 
in terme van die aantal klasse wat op die eerste twee vlakke van onderverdeling aangetref is, was Yahoo! die ander soekenjins ver voor. In vergelyking met die volledige uitgawes van Dewey, UDC en LCC sal die klassifikasiesisteme van die soekenjins egter nog baie uitgebrei moet word om dieselfde vlakke van spesifisiteit te bereik (Van der Walt 1997).

\section{Toepassing van klasssifikasiesisteme vir snuffel en soek in Internetgidse}

Klassifikasiesisteme word vir twee doeleindes gebruik in Internetgidse, naamlik (1) vir die fisiese rangskikking van inskrywings op die webbladsye met die oog op snuffelsoektogte ('browse'), en (2) as 'n toegangspunt waaronder spesifieke soektogte met behulp van 'n soekenjin se 'search'-fasiliteit uitgevoer kan word. Die resultate van die ondersoek na hierdie twee aspekte word in Tabel 1 saamgevat. Hoewel hierdie studie op die rol van klassifikasie fokus, is ter wille van 'n meer volledige prentjie van die variasies van onderwerpstoegang ook gelet op die voorsiening wat die Internetgidse mak vir soektogte onder verbale deskriptore (onderwerpshoofde) uit gekontroleerde indekseertale en onder sleutelwoorde in natuurlike taal (dit wil sê terme wat in die titels en teks van die elektroniese dokumente voorkom).

Dit blyk uit Tabel 1 dat 23 gidse klassifikasiesisteme met notasies op een of ander wyse benut, terwyl 22 gidse gebruik maak van verbale onderwerpsklasse, meestal alfabeties gerangskik. Uit eersgenoemde groep gebruik 21 gidse die klassifikasienommers as ordeningsmeganisme in snuffellyste. Die twee uitsonderings, Blue Web'n Content Categories en SOSIG, se breë onderwerpsklasse is alfabeties gerangskik en sou uit hierdie oogpunt dus by die groep 'Ander sisteme' aan die einde van die tabel ingedeel kon word.

In die Blue Web'n-gids word die Dewey-nommer tussen hakies na elke onderwerpskategorie verstrek en dit kan as soekterm gebruik word. By SOSIG lei die 'browse'-funksie van die stelsel na 'n alfabetiese lys van onderwerpe wat gekoppel is aan die notasies. Die notasies is egter nie in hierdie stadium sigbaar vir die gebruiker nie (soos by die Blue Web'n Content Categories) en dien bloot as meganisme om alle bronne oor die onderwerp wat die gebruiker uit die alfabetiese lys kies, bymekaar te bring.

Die meeste van die geklassifiseerde snuffellyste voorsien hiperteksskakels wat die soeker direk vanaf die indelings van die klassifikasiesisteem na lyste van inligtingsbronne neem, waar die bronne dan volgens die notasies gerangskik is. In enkele gevalle word verbale onderwerpshoofde (sonder notasies) vir die verdere indeling van bronne in 'n klas gebruik. Die UK Web Library se 'Browse interface' (of 'Classification browser') lei die soeker nie direk na lyste van inligtingsbronne nie, maar is eintlik net 'n uiteensetting van die hiërargie van Dewey-nommers. Die soeker kan dit gebruik om sy soektog te vernou totdat die spesifieke Dewey-nommer vir sy onderwerp opgespoor word. Die nommer kan dan as soekterm by die 'Dewey interface' ingesleutel word, vanwaar 'n geklassifiseerde lys van bronne opgespoor word. Dit is nie duidelik waarom daar nie vanaf die Browse interface direkte skakels na die lys van bronne verskaf word nie.

Slegs vyf uit die 23 gidse wat sisteme met notasies gebruik, maak egter voorsiening daarvoor dat die klassifikasienommers as soekterme ingevoer kan word in hulle 'Search'-dialoogblokkies. By enkele gidse word spesifiek vermeld dat meer as een klassifikasienommer per bron toegeken word, indien nodig.

'n Interesssante verskynsel is dat sewe uit die 21 gidse wat volgens notasies ingedeel is ook voorsiening maak vir snuffelsoektogte volgens alfabeties-gerangskikte onderwerpshoofde vir soekers wat hierdie benadering verkies. In sommige gevalle, byvoorbeeld Signpost, word 'n lys van bronne direk onder die onderwerpshoofde verstrek (net soos by die notasionele rangskikking), terwyl in ander gevalle die alfabetiese lys funksioneer as 'n indeks tot die klassifikasiesisteem, met skakels na die geklassifiseerde rangskikking van bronne, byvoorbeeld CyberDewey en CyberStacks(sm).

Die onderwerpshoofde vir hierdie alfabetiese rangskikkings is soms gebaseer op die verbale opskrifte wat langs die notasies in die geklassifiseerde gedeelte verskyn, byvoorbeeld by CyberDewey en die gids van die Universiteitskollege van Chester. Die Library of Congress Subject Headings (LCSH) word as basis gebruik vir die alfabetiese onderwerpsklasse waarvolgens bronne gerangskik word in BUBL LINK, Canadian Information by Subject, Signpost en INFOMINE.

\section{Deskriptore en sleutelwoorde as soekpunte}

Slegs BUBL en INFOMINE maak daarvoor voorsiening dat die LCSH-deskriptore wat aan bronne toegeken word as soekterme by hulle 'Search'-dialoogblokkies gebruik kan word. Mitchell (1996) bespreek die gebruik van LCSH in INFOMINE.

Sleutelwoorde kan baie meer algemeen as soekterme gebruik word. Tien van die 23 gidse wat sisteme met notasies gebruik, makk hiervoor voorsiening, terwyl slegs een van die sisteme met verbale onderwerpsklasse, naamlik The WWW Virtual Library, nie sleutelwoordsoektogte toelaat nie.

Twee variasies van sleutelwoordsoektogte word aangetref. By gidse wat nie ook volwaardige Internetsoekenjins is nie word die sleutelwoordsoektogte beperk tot die bronne wat in die gids opgeneem is. Dit is die geval by Blue Web'n, BUBL LINK, The Internet Public Library, die gidse van die Mid-Continent en Tempe openbare biblioteke, The UK Web Library, Webrary, NISS, SOSIG, Signpost, The Argus Clearinghouse, INFOMINE, Librarians' Index to the Internet, LookSmart, Lycos Top 5\% en Whatu-seek. Gewone soekenjins wat gidse as addisionele fasiliteit aanbied, gee meestai die keuse om die soektog te 
beperk tot die bronne in die gids, of om ' $\mathrm{n}$ volledige Internetsoektog te doen.

Sommige gidse het nie hulle eie soekenjins vir volledige Internetsoektogte nie, maar koppel die soeker aan 'n ander soekenjin wanneer die 'Search'-opsie gekies word. AOL NetFind gebruik byvoorbeeld Excite as soekenjin en Search.com gebruik Infoseek. Yahoo! doen outomaties 'n soektog in Alta Vista indien geen bronne in die gids self opgespoor word nie. Britannica Internet guide gee aan die soeker die keuse om aan te dui of die soektog tot die gids beperk moet word en of Alta Vista gebruik moet word om die hele Web te deursoek. Kommersiële soekenjins word ook soms gebruik by gidse wat net interne soektogte toelaat. Die Mid-Continent openbare biblioteek se gids en Signpost gebruik albei Excite.

\section{Bespreking: kenmerke van die ideale Internetgids}

Uit die voorgaande ontleding van die kenmerke van 'n verskeidenheid van Internetgidse kan 'n mens moontlik 'n beeld vorm van hoe die ideale gids behoort te lyk in terme van rangskikking en soekpunte:

Daar moet voorsiening gemaak word vir snuffelsoektogte sowel as doelgerigte, spesifieke onderwerpsoektogte. Dodd (1996:281) is van mening dat hierdie twee benaderings teruggevoer kan word na basiese verskille in menslike soekgedrag en selfs toegeskryf kan word aan linker- of regterbreindominansie by verskillende persone, wat meebring dat hulle voorkeur gee aan een van die twee benaderings. Vir die snuffelaar moet daar dus hiërargiese onderwerpslyste wees, terwyl 'n fasiliteit vir soektogte onder sleutelwoorde of deskriptore analitiese denkers se behoeftes moet bevredig.

Daar kan nie in die lig van die huidige ondersoek uitsluitsel gegee word oor wat die keuse moet wees tussen volledig sistematiese ordening soos wat die tradisionele biblioteekklassifikasiesisteme bied en die alfabeties-geklassifiseerde rangskikkings wat gebruik word in soekenjins en enkele ander gidse nie. Uit die ondersoek het geblyk dat beide tipes sisteme op redelike groot skaal en skynbaar met sukses gebruik word. Beide tipes het egter ook sonder twyfel bepaalde tekortkominge wat in die literatuur uitgewys word.

Nieteenstaande argumente wat aangevoer word om aan te toon dat die behoeftes vir klassifikasie op die Internet soveel verskil van die gewone biblioteekomgewing dat spesiale sisteme ontwikkel moet word (bv. Callery 1996), kry 'n mens tog die indruk dat die samestellers van soekenjins besig is om wiele wat al vir baie jare goed werk, te herontwerp. Taylor (1994:629) sê in hierdie verband:

'People in computing either don't know about the principles of organization developed by libraries in the last 150 years, or they seem to think that they couldn't possibly be applicable for electronic data.

So they are reinventing the wheel'.

Terwyl aanvaar kan word dat sisteme soos Dewey, UDC en LCC nie vir alle Internetgidse geskik sal wees nie, kan egter aanbeveel word dat spesiale klassifikasiesisteme vir die Internet saamgestel word met inagname van die gevestigde beginsels waarop biblioteekklassifikasiesisteme berus.

'n Netelige saak waaroor in die biblioteekwêreld al vir meer as honderd jaar geargumenteer word, is of klassifikasie breed of spesifiek moet wees. Indien verwag word dat 'n gids op die lang duur baie gaan uitbrei, en veral in ' $n$ akademiese of navorsingsomgewing, mag dit wys wees om van die begin af taamlik spesifiek te klassifiseer.

'n Alfabetiese lys van spesifieke onderwerpe ter aanvulling van 'n geklassifiseerde rangskikking, soos wat by enkele van die gidse waargeneem is, bied 'n nuttige alternatiewe snuffelbenadering, veral indien dit 'n omvattende gids met taamlik gedetailleerde onderverdelings is. Dit kan as onnodige duplikasie beskou word om lyste van verwysings na bronne in die geklassifiseerde sowel as in die alfabeties-spesifieke rangskikkings te verskaf. Die alfabetiese lys van terme kan eerder as ' $n$ indeks tot die klassifikasie dien, met hiperteksskakels wat die soeker met 'n klik van die muis na die toepaslike gedeeltes in die sistematiese deel van die gids neem.

Soos hierbo aangedui, is dit wenslik dat 'n gids ook 'n soekfunksie bied vir diegene wat direk na spesifieke onderwerpe wil soek sonder om deur die hiërargie van die klassifikasiesisteem te snuffel. As minimumvereiste moet sleutelwoordsoektogte moontlik wees, maar daar kan ook deskriptore uit 'n gekontroleerde taal soos LCSH an bronne toegeken word. Indien 'n biblioteekklassifikasiesisteem gebruik word om nommers aan individuele bronne toe te ken, behoort hierdie nommers ook as soekterme gebruik te kan word.

\section{Gevolgtrekking en samevatting}

Hierdie ondersoek het aangetoon dat klassifikasie reeds 'n beduidende rol speel in die organisering van bronne op die Internet. Die vraag is nie meer of klassifikasie 'n bydrae kan maak nie, maar eerder presies hoe bestaande sisteme aangepas of nuwe sisteme ontwerp moet word om ten beste in die elektroniese omgewing te kan funksioneer.

'n Verskeidenheid van gidse is opgespoor wat gebruik maak van tradisionele biblioteekklassifikasiesisteme sowel as alfabeties-geklassifiseerde indelings wat spesifiek vir die Internet ontwerp is. Deur ' $n$ ontleding van die vernaamste kenmerke van hierdie sisteme met betrekking tot rangskikking en soekpunte was dit moontlik om breë riglyne aan te beveel vir die samestelling van gidse van Internetbronne. Verdere evaluatiewe en vergelykende studies van Internetgidse, en moontlik ook Internetgebruikerstudies, is nodig om in meer besonderhede te bepaal wat die eienskappe van 'n ideale klassifikasiesisteem vir bronne op die Internet moet wees. 


\section{Summary}

The Internet is often regarded as an unorganized, rather chaotic collection of information sources. Search engines have been developed to enable information seekers to find their way on the Net, but they have to rely on natural language with all its associated problems. The question arises whether systematic arrangement by means of a classification scheme can offer a solution to the problems of information organization on the Internet.

The purpose of the investigation was to establish the extent of present use of classification on the Internet, which systems are being used, what the nature, characteristics and applications of these schemes are, and to formulate broad guidelines for classification in this electronic environment.

A large number of Internet guides (directories, channels, catalogues, virtual libraries) in which classification plays a role were identified. Forty-five of these were selected for the investigation. Of these 23 use classification schemes with notations and 22 use broad verbal subject classes, mostly with an alphabetico-classed arrangement. In the first group 15 guides use the Dewey decimal classification, two the Universal decimal classification, five the Library of Congress classification and one the Nederlandse Basisclassificatie. The alphabetico-classed schemes of the second group are unique to each guide. A brief description of each guide is given, including the URL.

It was found that the guides using DDC, UDC and LCC generally follow a policy of broad classification. Most of the alphabetico-classed schemes also tend to be broad, making provision for only three to four levels of hierarchical subdivision. A comparison between the library schemes and the concepts found in the main classes of the alphabetico-classed schemes showed marked differences between the two groups.

The classification schemes are used for two purposes in Internet guides: (1) the physical arrangement of entries on the web pages to make provision for browsing and (2) in a few cases to provide access points for specific searching with a search engine. The results of the investigation of this aspect as well as the provision made for verbal access points (descriptors from controlled languages and keywords from natural language) are presented in a table. It was found that facilities for keyword searching are provided in the majority of guides, but descriptors are used in very few cases.

In conclusion a number of guidelines for classification schemes in Internet guides are proposed. Provision should be made for browsing as well as specific subject searching. The compilers of dedicated schemes used in search engines should take heed of the established principles of library classification schemes. Broad classification can be acceptable in certain circumstances, but in large collections and especially in an academic or research environment it might be advisable to use specific classification from the start. A classified arrangement should be supplemented by an alphabetical browse list of specific subjects acting as an index to the classification scheme. The facility for specific searching should make provision for at least keyword searches, but where possible also for controlled descriptors and classification numbers.

\section{Verwysings}

Balas, J. 1996. Dewey and the Net. Computers in libraries, 16(1):46-47.

Callery, A. 1996. Yahoo! cataloging the Web, in Untangling the Web: proceedings of the conference sponsored by the Librarians Association of the University of California, Santa Barbara, and Friends of the USCB Library, April 26, 1996, ed. A.L. Duda. [Online]. Available: http://www.library.ucsb.edu/ untangle/callery.html

Chan, L.M. 1995. Classification, present and future. Cataloging \& classification quarterly, 21(2):5-17.

Collins, B.R. 1997. Webwatch. Library journal, 122(1):31-32.

Dodd, D.G. 1996. Grass-roots cataloging and classification: food for thought from World Wide Web subject-oriented hierarchical lists. Library resources and technical services, 40(3):275286.

Ensor, P. 1996. Web organization: use of the Library of Congress Classification. Technicalities, 16(3):11-12.

Feldman, S. 1997. Search engine watch: an outstanding and useful meta site. Online, 21(6):62.

Hawkins, D.T. 1996. Hunting, grazing, browsing: a model for online information retrieval. Online, 20(1):71-73.

Hyman, R.J. 1972. Access to library collections: an inquiry into the validity of the direct shelf approach, with special reference to browsing. Metuchen, N.J.: Scarecrow Press.

Internet Public Library: same metaphors, new service. 1997. American libraries, 28(2):56-59.

Liu, Jian 1996. Understanding WWW search tools. [Online]. 2nd update, Sept. 1996. Available: http://www.indiana.edu/ $\sim$ librcsd/search/

McKiernan, G. 1996. Casting the Net: the development of a resource collection for an Internet database, in Untangling the Web: proceedings of the conference sponsored by the Librarians Association of the University of California, Santa Barbara, and Friends of the USCB Library, April 26, 1996, ed. A.L. Duda. [Online]. Available: http://www.library.ucsb.edu/ untangle/mckiernan.html

McKiernan, G. 1997. Beyond bookmarks: schemes for organizing the Web, December 16, 1997. [Online]. Available: http:// www.public.iastate.edu/ CYBERSTACKS/CTW.htm

Mitchell, S. 1996. Library of Congress Subject Headings as subject terminology in a virtual library: the INFOMINE example, in Untangling the Web: proceedings of the conference sponsored by the Librarians Association of the University of California, Santa Barbara, and Friends of the USCB Library, April 26, 1996, ed. A.L. Duda. [Online]. Available: http://www.library.ucsb.edu/untangle/smitch.html

Notess, G.R. 1997. New features of the Web indexes. Online, 21(5):52-55.

Piontek, S. \& Garlock, K. 1996. Creating a World Wide Web resource collection. Internet research, 6(4):20-26.

Sullivan, D. (red.) c1998. Search engine watch. [Online]. Available: http://searchenginewatch.com/ (besoek op 7/3/ 1998). 
Taylor, A.G. 1994. The information universe: will we have chaos or control? American libraries, 25(7):629-632.

Van der Walt, M.S. 1997. The role of classification in information retrieval on the Internet: some aspects of browsing lists in search engines. In Knowledge organization for information retrieval: proceedings of the sixth International Study Conference on Classification Research, London, June, 1997. The Hague: International Federation for Information and Documentation:32-35.

Vellucci, S.L. 1996. Herding cats: options for organizing electronic resources. Internet reference services quarterly, $1(4): 9-30$.
Vizine-Goetz, D. 1996. Using library classification schemes for Internet resources, in Proceedings of the OCLC Internet Cataloging Project Colloquium, San Antonio (Texas), January 19. [Online]. Available: http://www.oclc.org/oclc/man/colloq/ v-g.htm

Williamson, N.J. 1997. Knowledge structures and the Internet. In Knowledge organization for information retrieval: proceedings of the sixth International Study Conference on Classification Research, London, June, 1997. The Hague: International Federation for Information and Documentation:23-27.

Woodward, J. 1996. Cataloging and classifying information resources on the Internet. Annual review of information science and technology, 31:189-220. 